\title{
Orçamento participativo: uma abordagem na perspectiva da Ciência da Informação
}

\author{
Participatory budgeting: an approach from \\ an Information Science perspective
}

Alex de Araujo LOPES

Isa Maria FREIRE2

\section{Resumo}

Este trabalho objetiva destacar a importância do orçamento participativo como fonte de inclusão social na sociedade intensiva de informação, em conjunto com os postulados da Ciência da Informação. O modelo participativo de gestão do orçamento participativo apresenta sinais de possibilidades de construção de um método provedor de democracia, e, nesse processo, a informação torna-se insumo inestimável. Nesse contexto, a Ciência da Informação surge como uma teia de formulações com laços concomitantes para que o acesso, a disseminação, o registro e a organização das informações produzidas sejam transformadas em realidades, sugerindo, ademais, proposições de ordem educativa para a cidadania. No atual momento de transição histórica e cultural da sociedade brasileira, comunidades e pessoas excluídas econômica e socialmente têm a possibilidade de participar do processo de gestão democrática mediante o orçamento participativo. Esses núcleos de compartilhamento de informações, conhecimentos e saberes tendem a contribuir para criar alternativas de transformação do espaço social, de modo a promover a inclusão dos grupos sociais menos favorecidos no acesso à informação.

Palavras-chave: Ciência da Informação. Inclusão social. Orçamento participativo. Políticas públicas.

\begin{abstract}
This work proposes highlighting the importance of participatory budgeting as a source of social inclusion in the intensive information society, in conjunction with the premises of Information Science. The model of participatory budget management shows signs of the possibility of constructing a method that provides democracy, in which case the information becomes an invaluable input. In this context, information science emerges as a web of formulations with concurrent ties, permitting the dissemination, recording and organization of the information produced to be transformed into reality, suggesting, moreover, propositions of an educational order for citizens. At the present moment of historical and cultural transition through which we are passing in Brazilian society, communities and economically and socially excluded individuals have the chance to participate in the process of democratic management through participatory budgeting. These clusters of information sharing, knowledge and wisdom tend to contribute to the creation of alternatives for the transformation of social space in order to promote the inclusion of disadvantaged social groups in terms of access to information.
\end{abstract}

Keywords: Information science. Social inclusion. Participatory budgeting. Public policy.

\footnotetext{
1 Professor, Autarquia do Ensino Superior de Garanhuns, Curso de Administração Geral. Granhuns, Pl, Brasil.

2 Professora Doutora, Universidade Federal da Paraíba, Departamento de Ciência da Informação. Campus I, Cidade Universitária, 58051-900, João Pessoa, PB, Brasil. Correspondência para/Correspondence to: I.M. FREIRE. E-mail: <isafreire@globo.com>.

Recebido em 15/5/2011 e aceito para publicação em 29/9/2011.
} 


\section{Introdução}

Este artigo discorre sobre o orçamento democrático na cidade de João Pessoa (PB) como proposta de inclusão social pelo caminho da socialização e promoção de acesso público à informação, a partir da construção de um protótipo de rede virtual de comunicação. Espera-se promover a mediação entre atores e agentes envolvidos no processo de orçamento participativo, em um dado regime de informação, como pressuposto de geração de informações cujo tear se consolida nas trocas, alimentação e realimentação de informações.

A socialização da informação é um pressuposto importante para construção de ambientes de inclusão, para os quais se requerem mecanismos de comunicação para que essa socialização seja de fato real. Seguindo esse raciocínio, emerge a Ciência da Informação no contexto do regime e ações de informação ${ }^{3}$ em conjunto com as tecnologias digitais para tornar possível reunir no ambiente virtual as informações e propostas do orçamento democrático no município de João Pessoa.

A proposta emergiu dos ideários do orçamento participativo, que tem como eixo a possibilidade de gestão para participação popular nos processos decisórios do Estado e a perspectiva da responsabilidade social da Ciência da Informação (Freire, 2001) com seus construtos e artefatos disponibilizados atual-mente, justificando dessa forma a formulação dos atores potenciais que dela necessitam. Na sociedade da informação, ofertar elementos que possibilitem alçar determinados grupos sociais à categoria de cidadãos é uma responsabilidade social inerente à Ciência da Informação.

Dessa forma, construir um artefato de comunicação e informação como tecnologia de mediação para compartilhamento de informações e conhecimentos sobre o orçamento participativo é fundamental para o êxito dessa proposta. Esse artefato, uma rede de comunicação e aprendizagem sobre o orçamento participativo, atuará entre o usuário e as fontes de informação, respeitando a visão de mundo dos usuários, sua linguagem e meios comunicativos, de forma a contribuir para a socialização da informação.

\section{Socialização da informação: uma abordagem}

A Ciência da Informação - sistematização e representação do conhecimento científico gerado - reflete sobre recursos e dispositivos propulsores de fluxos informacionais para geração de novos conhecimentos. Nesta sociedade com intenso fluxo e produtora de informação e conhecimento, as redes de comunicação, utilizando seus dispositivos, assumem papel vital para tornar a informação ainda mais relevante, como destaca Assmann (2000, p.15):

A sociedade da informação é a sociedade que está atualmente a constituir-se, na qual são amplamente utilizadas tecnologias de armazenamento e transmissão de dados e informação de baixo custo. Esta generalização da utilização da informação e dos dados é acompanhada por inovações organizacionais, comerciais, sociais e jurídicas que alterarão profundamente o modo de vida tanto no mundo do trabalho como na sociedade em geral.

Freire (2008, p.64) coloca mais expressivamente a presença da informação e do conhecimento na nova realidade social, já que está se iniciando a sociedade do aprendizado contínuo, na qual a valorização da informação e do saber ocupa um papel chave caracterizado pela exigência de um aprendizado ininterrupto, e os trabalhadores passam a lidar com novas exigências profissionais e sociais, já que:

[...] as tecnologias digitais de informação estão cada vez mais presentes em todos os segmentos da sociedade, concorrendo para que surjam novas formas em relação à produção e aquisição de saberes. [...] surgem novos processos, tais como a aprendizagem e o trabalho cooperativos assistidos por computador, que se traduz em aprendizagem cooperativa. Isso nos leva a uma realidadepossivel, onde cursos e treinamentos são ministrados à distância, e o trabalho pode ser efetuado por pessoas que estão em diferentes locais. De

\footnotetext{
3 O construto regime de informação, proposto por González de Gómez (1999, p.64), representa o"conjunto mais ou menos estável de redes sociocomunicacionais formais e informais nas quais informações podem ser geradas, organizadas e transferidas de diferentes produtores, através de muitos e diversos meios, canais e organizações, a diferentes destinatários ou receptores, sejam estes usuários específicos ou públicos amplos [...". Nessa perspectiva, a Ciência da Informação seria "aquela que estuda fenômenos, processos, construções, sistemas, redes e artefatos de informação, enquanto 'informação' for definida por ações de informação, as quais remetem aos atores que as agenciam, aos contextos e situações em que acontecem e aos regimes de informação em que se inscrevem" (González de Gómez, 2003, p.36).
} 
imediato, percebemos a possibilidade, também, de uma diminuição de custos operacionais, já que as pessoas não precisariam mais se deslocar para um 'local de trabalho' (grifo do autor).

Os artefatos tecnológicos dispostos em suas mais variadas usabilidades vêm provocando nas comunidades formas de comunicação e informação distintas, expressas na virtualidade. As informações transitam por diversos canais, em especial pela Internet: as informações, os fatos, as notícias e os dados que se originam das redes de TV, jornais, organizações, instituições públicas e privadas, além dos indivíduos nas redes sociais, transformam o cotidiano. Estão todos interligados por redes de comunicação.

Lévy (1994) discorre sobre os princípios que fazem com que o crescimento do ciberespaço se torne um espaço comunicacional que relaciona produtores e usuários em um mesmo contexto tecnológico. O primeiro é a interconexão, fundamental para manter o ciberespaço ligado através de redes; o segundo é a criação de comunidades virtuais, que seria a implantação da massa crítica unida por um interesse comum e participando de vários mecanismos de interação; o terceiro, de que trata o presente trabalho, é a inteligência coletiva, que propõe que a informação de todos para todos aumente a possibilidade de geração de novos conhecimentos.

Na dinâmica social atual, a Ciência da Informação assume papel de destaque na construção de elementos que promovam a participação popular no contexto político, social e econômico. Nessa leitura, Le Coadic (1996) reafirma o pensamento sobre a função social da Ciência da Informação, ao apontar que a sociedade necessita de uma ciência que estude as propriedades da informação e os processos de sua construção, comunicação e uso, diante de três categorias de mudanças: culturais, econômicas e tecnológicas. Para o autor, "a informação é um conhecimento inscrito (gravado) sob a forma escrita (impressa), oral ou audiovisual" (Le Coadic, 1996, p.7). No momento presente da sociedade, organizar as informações de forma lógica, em ambiente virtual de comunicação, ou seja, interagindo com a diversidade presente nas comunidades ou grupos, torna-se quase imperativo, haja vista que historicamente a sociedade brasileira sempre esteve a mercê do Estado. Neste momento histórico, há a possibilidade real de participação popular no processo de gestão democrática dos recursos, e uma dessas possibilidades resulta no orçamento participativo.

\section{Orçamento participativo: um empoderamento social}

No decorrer dos anos 1980, a redemocratização do País e o aprofundamento da crise econômica expuseram totalmente a crise do Estado. As principais características do funcionamento estatal no regime militar deixavam de atender às novas demandas sociais: centralidade excessiva, pouca capacidade gerencial, ineficiência na prestação de serviços, ausência de mecanismos democráticos de controle e participação, corrupção e estagnação estatal.

Passado esse tempo, as últimas décadas de produções tecnológicas intensas vêm exigindo grande articulação: os países ricos passaram a desenvolver uma proposta para a sociedade como um todo. Universidades, governos e empresas dividem entre si o papel de difundir o conhecimento existente e transformá-lo em novos produtos e serviços com o apoio de competências espalhadas pela sociedade. Nesta sociedade plural, as gestões deveriam ser marcadas pela promoção de acesso aos recursos, em especial a informação. Disponibilizar e compartilhar informações através de tecnologias operacionais, obje-tivando a socialização das informações produzidas, tornou-se vital para a inclusão de determinados grupos sociais no cenário da economia global, como explicitado porFreire (2004, p.27):

[...] desde o momento inicial da evolução da humanidade, a informação, no sentido geral de comunicação, esteve presente através da técnica e da linguagem, ou seja, da maneira de fazer determinados objetos, como roupas, armas, armadilhas, mapas, entre outros, e da forma de transmitir o conhecimento sobre esse fazer [...].

O orçamento participativo é fruto de ideias amparadas em valores, planejamento e organização sociopolíticos da nossa sociedade com a participação popular nos diálogos sobre as diretrizes de investimentos do Estado. As ideias, os sentidos, a cultura de determinadas práticas sociais estão embasadas no que se chama de paradigma, entendido não apenas como modelo ou padrão, mas também como um campo complexo de conceitos que contém e comporta uma determinada 
concepção de homem e de mundo e das relações que se estabelecem entre sujeito e objeto do conhecimento.

Nesse sentido, a participação popular nas decisões do uso dos recursos públicos se caracteriza como princípio norteador do constructo da cidadania, haja vista que essa prática se baseia no planejamento, uma fonte de inclusão social que, com seus resguardos, guarda uma profunda similaridade com a cidadania. Como assinala Marquetti (2008, p.15):

A democracia participativa enfatiza a presença
dos cidadãos comuns nos processos de tomada
de deci-sões, colocando-os em condições
comuns nos processos de tomadas de decisões,
colocando-os em condições de igualdade com
as elites econômicas e sociais. Para isso, é de
grande relevância que esses cidadãos ou seus
representantes tenham um papel central na defi-
nição da agenda.

A participação popular na discussão da aplicação dos recursos públicos representa um esforço para criar condições institucionais favoráveis à emergência da cidadania, em novas formas de gestão socioestatal, na qual a sistemática "partilha de poder"baseada em critérios objetivos, impessoais e universais é o elemento fundamental.

O orçamento participativo é um mecanismo de gestão que, alinhado às tecnologias informacionais, possibilita o empoderamento de determinados grupos sociais; como observa Fedozzi (2001, p.93): "interpretado como uma estratégia de promoção da cidadania no Brasil, o orçamento participativo distancia-se, portanto, da longa tradição autoritária que caracteriza a sociedade brasileira". Estratégico e dinâmico, o orçamento participativo tende a preencher o vácuo deixado por um Estado segregador, pois, com seu processo elaborado a partir de assembleias populares, torna-se um referencial do e para o País, haja vista que traz para o centro da discussão o Munícipio e o Estado, forçando este último a trabalhar dentro do planejamento definido pelo primeiro, como salientado por Balaban (2006, p.29):"nesse sentido, a aproximação entre vários órgãos do Estado e as organizações da sociedade civil que realizam o controle sobre políticas públicas tem sido fator essencial para a melhoria da qualidade do gasto público e o exercício da cidadania". É válido lembrar que, na sociedade da informação, a própria informação torna- -se vital para a promoção das alterações de estruturas; como afirma Araujo (1994, p.84):

Se a informação éa mais poderosa força de trans-
formação do homem, [o] poder da informação,
aliado aos modernos meios de comunicação de
massa, tem a capacidade ilimitada de trans-
formar culturalmente o homem, a sociedade e a
própria humanidade como um todo.

Todavia, isso não é suficiente para a concretização das ações de informação. São necessários outros mecanismos que possibilitem levar a cabo tal intento, como o uso das tecnologias ou artefatos de comunicação e informação que atuam como mediadores entre a informação disponível, por exemplo, sobre orçamento participativo e os grupos formuladores, defensores e utilitários da gestão participativa. Ademais, essas tecnologias de informação e comunicação por si mesmas não resolvem problemas sociais, embora possam prover um suporte eficiente para soluções eficazes e ajudar no estabelecimento de "pontes" entre elementos formais e redes sociais informais existentes em comunidades locais.

Nesse contexto, torna-se vital a troca de experiências entre usuários e ao mesmo tempo o acesso à grande quantidade de informações produzidas sobre orçamento participativo, de modo que a possibilidade de cidadania torne-se real.

Os profissionais da comunicação e da informação também se tornaram relevantes para o desenvolvimento da sociedade, em decorrência do papel social de facilitar a comunicação entre usuários de conhecimento e fontes que produzem esse recurso e o disponibilizam como informação. Esse papel se realiza nas atividades e mecanismos através dos quais a informação circula no sistema de comunicação social, em especial nas redes de comunicação. Nesse processo, novas oportunidades para transferência efetiva da informação e do conhecimento podem ser criadas, de modo a apoiar atividades que fazem parte do próprio núcleo de transformação da sociedade (Wersig; Neveling, 1975. p.128).

Nesse sentido, um protótipo de rede virtual de comunicação e informação sobre a prática de orçamento participativo representa uma ação de informação para criar a cultura participante no ambiente virtual: um ambiente de discussão e troca de informações em que um 
processo socioeducativo se configure como força potencializadora de inclusão dos seus respectivos "mundos". Nas palavras de Freire (2000, p.101):

[...] construir um produto de informação a partir da interação com seus usuários potenciais, levando em consideração sua visão de mundo, suas formas de expressão e meios de comunicação, de modo a contribuir para o desenvolvimento de instrumentos de socialização da informação. Um produto de informação a partir do conhecimento próprio das pessoas que poderão vir a usá-lo, na sociedade [...].

Considerar as variáveis usuário e sistema para que o produto seja interativo e inclusivo, condicionado pela informação relevante e por usuários potenciais, é imperativo para gestar uma inteligência coletiva, como expressa Lévy (2001, p.135):

[...] a inteligência coletiva não é um conceito exclusivamente cognitivo. Inteligência deve ser compreendida aqui como na expressão"trabalhar em comum acordo" [...]. Trata-se de uma abordagem de caráter bem geral da vida em sociedade e de seu possível futuro [...]. Essa visão de futuro organiza-se em torno de dois eixos complementares: o da renovação do laço social por intermédio do conhecimento e o da inteligência coletiva propriamente dita.

Esse protótipo tende a tornar-se uma ferramenta estratégica e dinamizadora para esboçar certa diminuição do grave abismo que permeia a sociedade brasileira. Para construir a cidadania e promover a inclusão nesta sociedade intensiva de informações, o acesso e sua transferência passam a ser importantes insumos na cadeia produtiva; como destaca Assmann (2000, p.15): "é a sociedade que está atualmente a constituir-se, na qual são amplamente utilizadas tecnologias de armazenamento e transmissão de dados e informação".

\section{Gestão da informação: criando oportunidades de socialização}

No cerne das transformações tecnológicas vigentes, uma nova configuração de comunicação direciona o futuro, ganha um caráter estrutural e aparece como direção de convergência de todas as mudanças. Nesse contexto, a busca por uma reformulação da cidadania informacional num dado momento objetiva apro- fundar o campo de relações democráticas entre o governo e a cidadania; noutro momento, propõe-se a inovar as estruturas de articulação e reformular a distribuição de responsabilidades.

Desde tempos remotos, a informação é recurso de poder pela vinculação do desenvolvimento com a capacidade de uma sociedade em gerar e aplicar conhecimentos. Todavia, no século XX, ocorreu uma explosão de produções tecnológicas ao mesmo tempo em que sua organização e disseminação deram-se por novos ambientes, como a virtualidade, como atesta Freire (2000, p.102):

No século XX, houve grande desenvolvimento em várias áreas do conhecimento, principalmente na criação de novas tecnologias de informação lideradas pelo computador. Neste contexto, a informação ganha cada vez mais relevância e o ato de aprender se torna uma necessidade constante para acompanhar as mudanças que ocorrem na sociedade.

O orçamento participativo é uma realidade para populações marginalizadas pelas políticas públicas em geral. As gestões nas quais a transparência e a responsabilidade sejam o foco tornam-se o eixo para encaminhamentos das mudanças desse paradigma excludente, que vem passo a passo demonstrando ser uma inovação gerencial idealizada pela revolução cubana de 1959 e trazida para o Brasil por exilados do golpe militar de 1964. No início do século XXI, o orçamento participativo se apresenta como dispositivo, testado seu valor no arriscado terreno das instituições marcadas pelo clientelismo, no processo de reconhecer o homem como capaz de se incluir ao ideário da cidadania, conforme apontado por Felix (2002, p.111):

[...] o OP [orçamento participativo] começa a expandir o raio da sua influência para todo o país e para o exterior. Há nisso mais do que um prêmio à coerência e à perseverança: há o reconhecimento por um leque amplo de setores democráticos e de esquerda da importância desse mecanismo inovador, quase revolucionário, na gestão pública.

A Ciência da Informação, apoiada em tecnologias intelectuais e digitais, sustenta as novas demandas de informação e conhecimento através de seus mecanismos organizacionais de gerenciamento da informação: 
[Na] sociedade intensiva de conhecimento, que produz e consome grandes quantidades de informação, as redes de comunicação de dados e troca de mensagens têm um papel importante. Dentre estas redes, destaca-se a Internet, em especial pela demanda para criação de novas tecnologias da informação (Freire, 2000, p.102).

Nessa nova reconfiguração social, a participação popular impulsionada por instrumentos disseminadores de informação em ambientes socializantes como o ciberespaço é fundamental na construção de comunidades cidadã, pois, como lembra Freire (2000, p.103),"é no espaço social, político e econômico, que ocorre o fenômeno da produção e circulação da informação". Instrumentos que possibilitem troca de ideias e busca de informações, na medida em que a sociedade está rompendo paradigmas e criando outros, no ciberespaço, em ambientes interativos de construção de estoques e trocas de informação, criando a cultura de rede anunciada por Lévy (1994, p.3):

O ciberespaço, interconexão dos computadores do planeta, tende a tornar-se a principal infraestrutura de produção, transação e gerenciamento econômicos. Será em breve o principal equipamento coletivo internacional da memória, pensamento e comunicação. Em resumo, em algumas dezenas de anos, o ciberespaço, suas comunidades virtuais, suas reservas de imagens, suas simulações interativas e sua irresistível proliferação de textos e signos serão o mediador essencial da inteligência coletiva da humanidade.

Inteligência coletiva é um termo desenvolvido pelo sociólogo Pierre Levy. Trata-se de um princípio a partir do qual as inteligências individuais são somadas e compartilhadas por toda a sociedade, potencializadas com o advento de novas tecnologias de comunicação, como a Internet, que "possibilita a partilha da memória, da percepção, da imaginação. Isso resulta na aprendizagem coletiva, troca de conhecimentos" (Levy, 1994, p.20). Seguindo a trilha do autor, encontra-se a ideia da nova interatividade social entre a tecnologia informacional coletiva e a democracia, de forma que:

O espaço cibernético introduz um novo tipo de interação que a gente poderia chamar de Todos e Todos, que é a emergência de uma inteligência coletiva. Do interior do espaço cibernético encontramos uma va-riedade de ferramentas, de dispositivos, de tecnologias intelectuais. Por exemplo, um aspecto que se desenvolve cada vez mais, nesse momento, é a inteligência artificial. Há também os hipertextos, os multimídia interativos, simulações, mundos virtuais, dispositivos de telepresença [...] (Levy, 1994, p.27).

A ideia postulada pelo presente trabalho entende o caminho que a democracia percorre para que a interligação dos sujeitos geste ambientes coletivamente discutidos, quando:

Temos, portanto, os meios de restauração de uma
democracia direta e em grande escala, porque,
até agora, a democracia direta só podia funcionar
em pequena escala, fazendo com que milhares
de pessoas espalhadas em territórios mais dis-
tantes não fossem envolvidas. Com o uso de novos
instrumentos técnicos dá para fazer uma demo-
cracia direta distinta do sistema de representação
(cuja organização política remete a um centro
de decisão e que está completamente obsoleta
na medida em que é tecnicamente obsoleto
que as decisões sejam centralizadas) (Levy, 1994,
p.7).

Nesse cenário de grandes produções, as informações devem ser registradas, organizadas em sistemas que possibilitem o acesso em um suporte tecnológico que permita que o conjunto de estoques seja administrado como uma rede de comunicação e aprendizagem, tal como propõe este trabalho de pesquisa.

\section{Considerações Finais}

Orçamento participativo e Ciência da Informação são instrumentos que se entrelaçam na busca de elementos que aprimorem os sujeitos para que o acesso à informação torne-se um direito de todos. Romper estruturas de domínio requer ajustes, equilíbrios e mediações com debates, diálogos e tecnologias mediadoras entre atores. Suas relações ultrapassam o centro de interesses por parte daqueles que fazem da política seus próprios alinhamentos. A construção de mecanismos de inclusão se reporta ao imperativo urgente para um país tão desigual e injusto como o Brasil. Empreender uma permanente atitude critica das ações e de controle das políticas públicas é uma característica de comunidades politizadas.

De forma geral, a produção de tecnologias que possibilitem a comunicação e o acesso à informação sobre orçamento participativo, a partir de um modelo inte- 
rativo de produção e transferência da informação, torna-se relevante para o empoderamento social de grupos desfavorecidos. Esse modelo deve privilegiar a participação popular, proporcionando impulsionadores para comunicações diretas, com promoção socioeducatica da comunidade, formulando, assim, uma plataforma de cooperação e colaboração via web, entre atores e agentes envolvidos no processo.

Nesse sentido, um protótipo de rede de comunicação virtual - cujo eixo é a socialização da informação sobre orçamento participativo -, ambientado na inteligência coletiva (ICOX), plataforma tecnológica desenvolvida na Universidade Federal do Rio de Janeiro, apresenta-se como ferramenta adequada ao desenvolvimento de uma metodologia participativa que promova a concretização do objetivo presente. Para tanto, há a preocupação de trazer para o contexto local, métodos e teorias compatíveis com as realidades e prioridades próprias de cada grupo. Os problemas devem ser relativizados e abordados com a participação dos sujeitos em função de contextos díspares, mas discutidos dentro da visão de uma Ciência da Informação comprometida com sua função social. Certamente, tal mudança epistemológica implica também uma recriação dos processos de recuperação e transferência de informação.

Assim, é no âmbito local, no quotidiano das vivências reais, que os problemas, na sua multidimensionalidade, são percebidos, simultaneamente, com a necessidade de articulação entre respostas, entre sistemas, na forma de redes e parcerias, cujo escopo passa pelo reforço da condição de cidadania efetiva e ativa, dos indivíduos em situação de exclusão social. É, também, no local que mais e melhor deve se realizar a democracia, numa matriz de intervenção participada entre agentes e sujeitos, enquanto atores sociais, concretizando em cada território um mundo mais justo, humanizado e solidário.

\section{Referências}

ARAUJO, V.M.R.H. Sistemas de recuperação da informação: nova abordagem teórico-conceitual. 1994. Tese (Doutorado em Comunicação e Cultura) - Escola de Comunicação, Universidade Federal do Rio de Janeiro, Rio de Janeiro, 1994.

ASSMANN, H. A metamorfose do aprender na sociedade da informação. Ciência da Informação, v.29, n.2, p.7-15, 2000.

BALABAN, D.S. A importância de conselhos de alimentação escolar: o controle de políticas públicas sob a ótica da cidadania. In: SOUZA, D.B. (Org.). Acompanhamento e controle social da educação: fundos e programas federais e seus conselhos locais. São Paulo: Xamã, 2006.

FEDOZZI, L. Práticas inovadoras de gestão urbana: o paradigma participativo. Revista Paranaense de Desenvolvimento, n.100, p.93-107, 2001.

FELIX. R.S. Orçamento participativo: teoria e prática. São Paulo: Cortez, 2002.

FREIRE, G.H.A. Construindo um hipertexto com o usuário. Ciência da Informação, v.29, n.3, p.101-110, 2000.

FREIRE, G.H.A. Comunicação da informação em redes virtuais de aprendizagem. 2004. Tese (Doutorado em Ciência da Informação) - Escola de Comunicação, Universidade Federal do Rio de Janeiro, Rio de Janeiro, 2004.

FREIRE, G.H.A. Redes virtuais de aprendizagem na sociedade e na pesquisa. Encontros Bibli, v.13, n.25, p.55-67, 2008.

FREIRE, I.M. A responsabilidade social da ciência da informação elou a consciência possível no campo científico. 2001. Tese
(Doutorado em Ciência da Informação) - Escola de Comunicação, Universidade Federal do Rio de Janeiro, Rio de Janeiro, 2001.

GONZÁLEZ DE GOMÉZ, M.N. Da política de informação ao papel da informação na política contemporânea. Revista Internacional de Estudos Políticos, v.1, n.1, p.57-93, 1999.

GONZÁLEZ DE GOMÉZ, M.N. Escopo e abrangência da ciência da informação e a pós-graduação na área: anotações para uma reflexão. Transinformação, v.15, n.1, p.31-43, 2003.

LE COADIC, Y.F. A ciência da informação. Brasília: Briquet de Lemos, 1996.

LÉVY, P. A Emergência do ciberspace e as mutações culturais. Palestra realizada no Festival Usina de Arte e Cultura, promovido pela Prefeitura Municipal de Porto Alegre, outubro, 1994. Disponível em: <http://www.caosmose.net/pierrelevy/ aemergen.html>. Acesso em: 3 ago. 2010.

LÉVY, P. Em defesa da inteligência coletiva. Entrevista de Fábio Fernandes. Jornal Nova-e, 2001. Disponível em: <http:// www.miniweb.com.br/biblioteca/Artigos/Pierre_Levy>. Acesso em: 10 set. 2010.

MARQUETTI, A.; CAMPOS, G.A.; PIRES, R. Democracia participativa e redistribuição: análise de experiências de orçamento participativo. São Paulo: Xamã, 2008.

WERSIG, G.; NEVELING, U. The phenomena of interest to Information Science. The Information Scientist, v.9, n.4, p.127-140, 1975. 
